\title{
Low Pressure Catalytic Combustion of Hydrogen on Palladium
}

\author{
Xi Wang1, Yixiang Shi1 ${ }^{*}$, Ningsheng Cai1, Xiaocheng Lv², Wei Yao \\ ${ }^{1}$ Key laboratory for Thermal Science and Power Engineering of Ministry of Education, Department of Thermal \\ Engineering, Tsinghua University, Beijing, China \\ ${ }^{2}$ China Academy of Space Technology, Zhongguancun Nandajie, Beijing, China \\ Email: ${ }^{*}$ shyx@tsinghua.edu.cn
}

Received December 2014

\begin{abstract}
Exhausts of airship fabric bag in the stratosphere such as hydrogen which can be used for fuels by using catalytic combustion method. This can save the extra fuels used in the power system. $\mathrm{Pd} / \gamma$ $\mathrm{Al}_{2} \mathrm{O}_{3}$ catalyst was prepared in this work by impregnation method and the $\mathrm{H}_{2}$ catalytic combustion reaction kinetic was investigated between the pressure of $3.6 \mathrm{kPa}$ and $101.3 \mathrm{kPa}$. The effects of temperature, pressure and gas composition ratio were studied in the paper. According to the experiment results, the increase of temperature increases the $\mathrm{H}_{2}$ conversion. The parameter pressure has a positive effect on $\mathrm{H}_{2}$ reaction kinetics and low concentration of $\mathrm{H}_{2}$ in mixtures shows better performance. The dependence of temperature on $\mathrm{H}_{2}$ reaction rate becomes more sensitive in high pressure.
\end{abstract}

\section{Keywords}

Airship, Hydrogen, Catalytic Combustion, Impregnation, Reaction Kinetic

\section{Introduction}

The airship fabric bag emissions of dilute hydrogen can be used in the power generation system by low temperature catalytic combustion technology. Due to the low pressure in the stratosphere, the application of catalytic combustion in stratospheric airship power generation system provides the advantages of low ignition temperature at lean combustion conditions, low pollution emissions, high combustion efficiency and stability [1]-[6] when compared with conventional combustion technology. Exothermic energy obtained from hydrogen catalytic combustion reaction can be provided to the power generation system as heat source which avoids carrying additional fuels into the stratosphere.

For the catalysts of the low temperature catalytic combustion of hydrogen, noble metal catalysts such as palladium and platinum have attracted large attention because of their high catalytic combustion activity and relative simple preparation method [7] [8]. Depending on the catalysts, different wash coats are adopted such as $\mathrm{Al}_{2} \mathrm{O}_{3}, \mathrm{CeO}_{2}$ et al. The wash coats should have large specific surface area and high thermal stability [9] [10] to

\footnotetext{
${ }^{*}$ Corresponding author.
} 
improve the dispersity of the active component and activity of the reactants.

While in the stratosphere the pressure is between $5.5 \mathrm{kPa}$ and $1.2 \mathrm{kPa}$ [11], the $\mathrm{H}_{2}$ reaction kinetics in low pressure and atmospheric pressure are differed from each other. Consequently, it is important to find out the difference between each other. This study focused on experiment studies of low pressure hydrogen catalytic combustion on $\mathrm{Pd} / \gamma-\mathrm{Al}_{2} \mathrm{O}_{3}$ catalyst with the tested pressure varying from $3.6 \mathrm{kPa}$ to $101.3 \mathrm{kPa}$. In the experimental part, a fixed bed reactor experiment set-up was used, in which different pressures were tested between the reaction temperature of $100^{\circ} \mathrm{C}$ and $150^{\circ} \mathrm{C}$. Additionally, different ratios of the fuel to oxidizer were applied to investigate the effect of $\mathrm{H}_{2}$ concentration on the reaction kinetics.

\section{Experiment}

\subsection{Experiment Set up}

In the present work, the sketch of the fixed bed quartz reactor set-up is shown in Figure 1. The reactor is made up of quartz glass tube that has a diameter of $1.1 \mathrm{~cm}$. Catalysts are filled into the fixed tray in the middle of the reactor and thermocouple is attached to it to test the temperature. The furnace is used for ignition of the reaction if needed. All relevant products in the outlet are detected by mass spectroscopy (MS) measurement device. When the experiments are operated below the atmospheric pressure, the vacuum pump is used to make sure a low pressure atmosphere in the reactor. And the vacuum regulating valve is used to adjust the pressure to the testing pressure in the reactor.

\subsection{Catalyst Preparation and Characterization}

The $\gamma-\mathrm{Al}_{2} \mathrm{O}_{3}$ supported $\mathrm{Pd}$ catalyst was prepared by impregnation method. The substrate is alumina spherical grain that has a diameter of about $1 \mathrm{~mm}$. Pd was incorporated in the substrate by impregnation from $\mathrm{Pd}\left(\mathrm{NO}_{3}\right)_{2}$

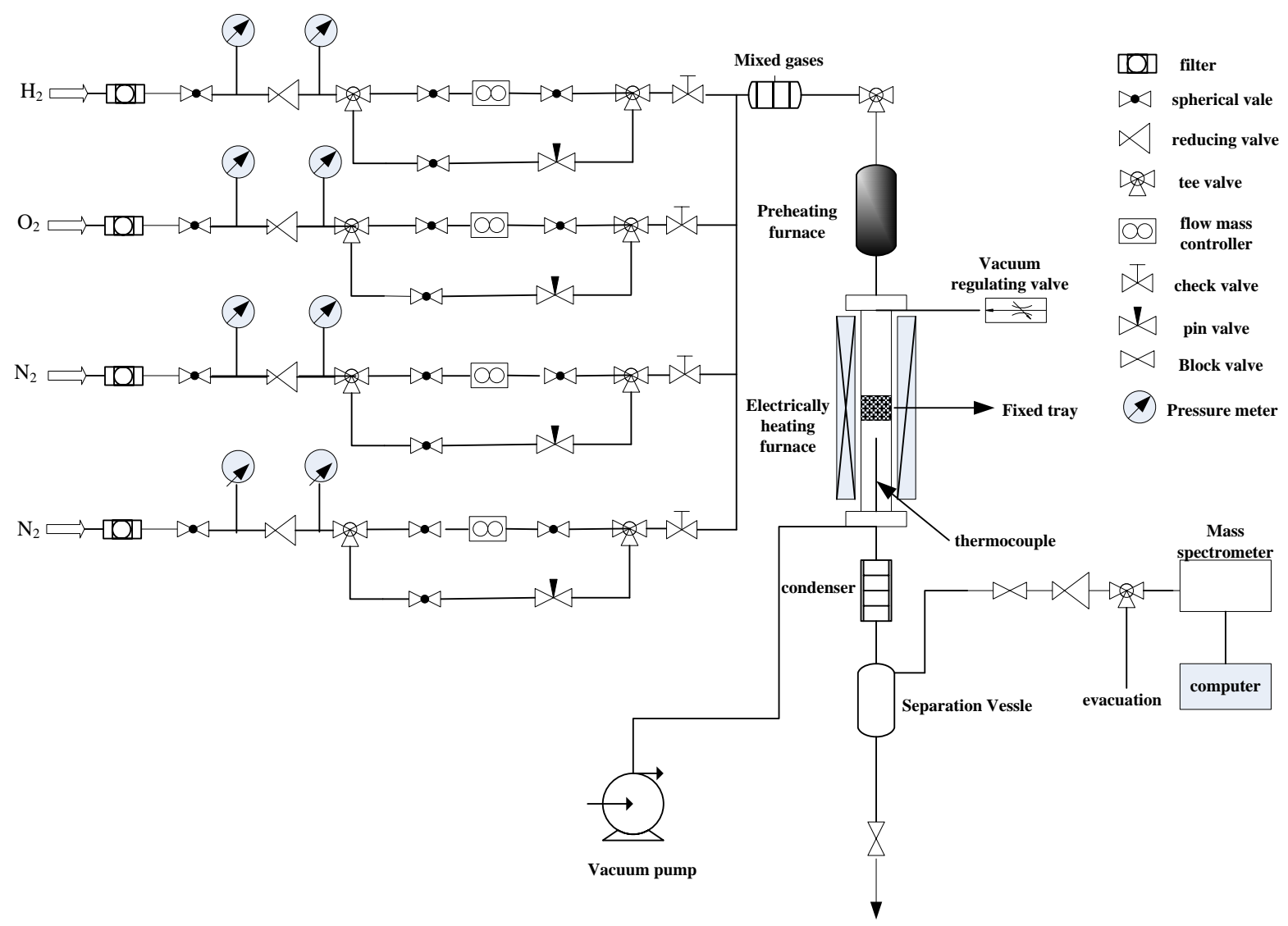

Figure 1. Schematic diagram of fixed bed reactor. 
aqueous solution. The catalyst was heated by oil bath at $120^{\circ} \mathrm{C}$ for $2 \mathrm{~h}$ and dried at $120^{\circ} \mathrm{C}$ for $30 \mathrm{~min}$. Subsequently it was calcined at $500^{\circ} \mathrm{C}$ for $10 \mathrm{~h}$. The mass percent of Pd is $3.9 \mathrm{wt} \%$.

Specific surface area of the substrate was measured by the adsorption of $\mathrm{N}_{2} \mathrm{using}$ the Micromeritics ASAP2000 specific surface area analyzer. According to the result, the specific surface area was $280.5 \mathrm{~m}^{2} \cdot \mathrm{g}^{-1}$ and it is large enough to be the catalyst supporter.

The prepared catalyst was characterized by powder X-ray diffraction (XRD), scans were performed over a $2 \theta$ range from $10^{\circ}$ to $90^{\circ}$. The materials are shown in Figure 2, indicating that the active catalyst phase is PdO. In the characterization, the diffraction peak of $\mathrm{PdO}$ exists in the diffraction angle of $35^{\circ}, 55^{\circ}, 60^{\circ}$. According to the microstructure characterization shown in Figure 3, the small PdO particles are distributed well on the surface of $\mathrm{Al}_{2} \mathrm{O}_{3}$ support and the aggregation of the PdO particles is not obvious. The EDS analysis in point 1 is shown in Table 1 and the weight ratio of Al to Pd is close to 1.

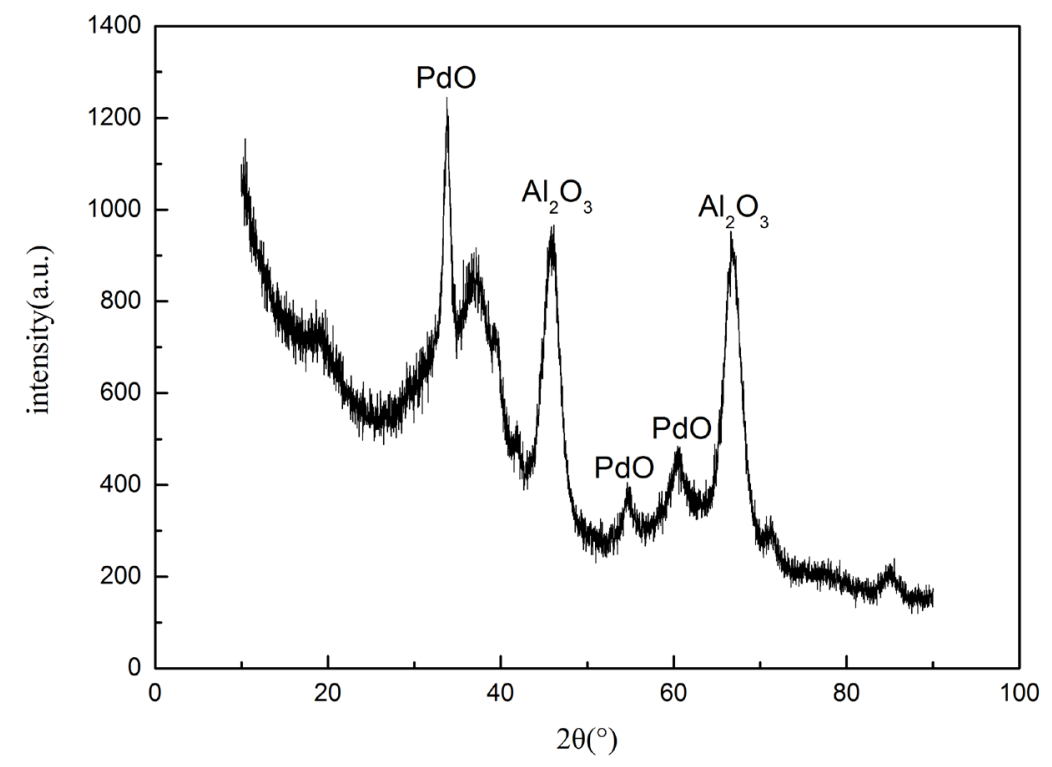

Figure 2. XRD of catalyst before testing.

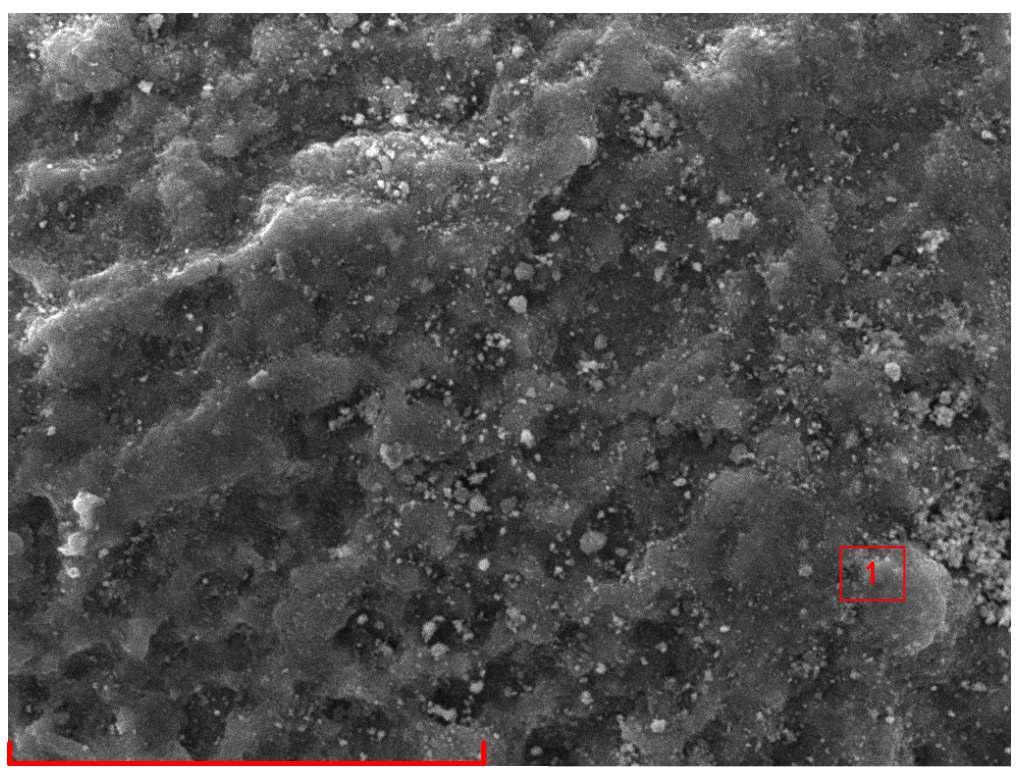

$60 \mu \mathrm{m}$

Figure 3. SEM image of $\mathrm{Pd} / \gamma-\mathrm{Al}_{2} \mathrm{O}_{3}$ catalyst before testing. 


\subsection{Measurement Conditions}

To investigate the catalytic activity of $\mathrm{H}_{2}$ on $\mathrm{Pd} / \mathrm{Al}_{2} \mathrm{O}_{3}$ in atmospheric pressure and the vacuum pressure, a series of experiments were carried out at different operation conditions such as total reaction pressure, $\mathrm{H}_{2} / \mathrm{O}_{2}$ equivalence ratio, temperature. The hydrogen and oxygen mixtures were diluted by nitrogen at total flow rate of 0.056 standard liter per minute (slpm). The furnace was used to ignite the reaction by heating up the reactor until light off occurs. The mass of the catalyst was 0.02 g. In addition, more $\mathrm{Al}_{2} \mathrm{O}_{3}$ sphere particles without impregnating active component Pd were filled in the reactor.

\section{Results and Discussion}

\subsection{Effect of Total Reaction Pressure on the Catalytic Combustion Performance}

Reaction pressure is an important parameter of $\mathrm{H}_{2}$ catalytic combustion reaction kinetics. In this paper three different pressures were adopted to study the influence of pressure on catalytic activity. Experiment operating conditions are listed in Table 2. The molar ratio of $\mathrm{H}_{2}$ to $\mathrm{O}_{2}$ is 0.6 which means equivalence ratio is 0.3. As can be observed in Figure 4, results show that the conversion of $\mathrm{H}_{2}$ increases with increasing pressure. The slow decrease of conversion is seen from atmospheric pressure of $101.3 \mathrm{kPa}$ to low pressure $3.6 \mathrm{kPa}$ indicating that pressure has a gentle influence on $\mathrm{H}_{2}$ conversion performance. At $125^{\circ} \mathrm{C}$, the conversions are 0.58 and 0.56 respectively. Though pressure decreases by $1 / 28$ of atmospheric pressure, the conversion has decreased by $2 \%$ displayed by experiment results. This phenomena is similar to the experimental results conducted by Michael [12]. In the experiments, the reaction rate of methane catalytic combustion on $\mathrm{Pt} / \mathrm{Al}_{2} \mathrm{O}_{3}$ catalyst increases with increasing pressure above atmospheric pressure. The study of the effect of pressure on $\mathrm{H}_{2}$ conversion performance indicates that $\mathrm{H}_{2}$ catalytic combustion in low pressure environment conditions is available and can achieve good performance as in atmospheric pressure.

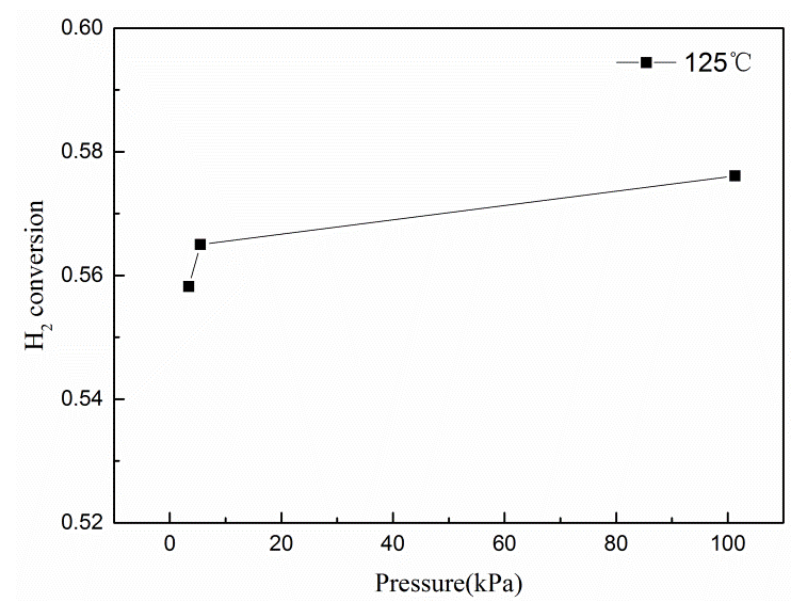

Figure 4. $\mathrm{H}_{2}$ conversion in different pressures at $125^{\circ} \mathrm{C}$.

Table 1. The element contents in point 1.

\begin{tabular}{ccc}
\hline Element & Weight ratio (\%) & Atom ratio (\%) \\
\hline $\mathrm{O}$ & 23.63 & 45.36 \\
$\mathrm{Al}$ & 38.38 & 43.68 \\
$\mathrm{Pd}$ & 37.99 & 10.96 \\
\hline
\end{tabular}

Table 2. Main parameters of experiment study.

\begin{tabular}{ccc}
\hline Reactants molar ratio & $\mathrm{H}_{2}: \mathrm{O}_{2}: \mathrm{N}_{2}=0.6: 1: 4$ \\
\hline Temperature $\left({ }^{\circ} \mathrm{C}\right)$ & 125 \\
Pressure $(\mathrm{kPa})$ & 101.3 & 5.5 \\
\hline
\end{tabular}




\subsection{Effect of Temperature on the Catalytic Activity}

The effect of temperature on the lean burn hydrogen catalytic combustion at the equivalence ratio of $0.3\left(\mathrm{H}_{2} / \mathrm{O}_{2}=\right.$ 0.6) are shown in Figure 5. It is observed that at the pressure of $3.6 \mathrm{kPa}$, hydrogen conversion increases by $5.6 \%$ from $100^{\circ} \mathrm{C}$ to $150^{\circ} \mathrm{C}$, while at $5.5 \mathrm{kPa}$ and $101.3 \mathrm{kPa}$ the conversions increase by $6.4 \%$ and $6.5 \%$ respectively. The parameter temperature has a gentle positive influence on $\mathrm{H}_{2}$ conversion. Theoretically, high temperature is beneficial for the improvement of $\mathrm{H}_{2}$ reaction kinetics. Comparing the effects of pressure with temperature, the influence of temperature in improving reaction kinetics is a little larger than pressure.

\subsection{Effect of Equivalence Ratio on the Catalytic Activity}

The different inlet reactants ratios of $\mathrm{H}_{2}$ to $\mathrm{O}_{2}$ were investigated at different pressures on the $\mathrm{H}_{2}$ catalytic activity. As shown in Figure 6, it is found that hydrogen conversion increases with decreasing equivalence ratio which indicates that the increase in the concentration of $\mathrm{H}_{2}$ lead to the decrease of hydrogen conversion. This may be due to the reason that the diffusion of $\mathrm{H}_{2}$ on the catalyst surface is inhibited in high $\mathrm{H}_{2}$ concentration conditions. More active reaction sites are occupied by $\mathrm{H}_{2}$ molecules through adsorption process. This in turn increases the reaction pathway between $\mathrm{H}_{2}$ and $\mathrm{O}_{2}$ molecules that leads to the decrease of $\mathrm{H}_{2}$ conversion. Therefore, the equivalence ratio of $0.3\left(\mathrm{H}_{2} / \mathrm{O}_{2}=0.6\right)$ is the optimal choice in whatever low pressure or atmospheric pressure.

\subsection{The Dependence of Temperature on $\mathrm{H}_{2}$ Reaction Rate at Different Pressures}

Figure 7 gives the dependence of temperature on $\mathrm{H}_{2}$ reaction rate with pressure varying from $3.6 \mathrm{kPa}$ to 101.3 $\mathrm{kPa}$ with $\mathrm{H}_{2} / \mathrm{O}_{2}=0.6$. The reaction rate $\mathrm{r}$ represents the $\mathrm{H}_{2}$ reaction moles per second. It can be seen that the reaction rate can be enhanced with increasing pressures. The increase of temperature also increases the reaction rate. With the increase of pressure, the improvement of temperature on reaction rate becomes more significant. Table 3 gives the expressions of $\mathrm{H}_{2}$ reaction rates in different pressures. Obviously, when the pressure gets higher, the dependence of temperature on $\mathrm{H}_{2}$ reaction rate becomes larger. In the low pressure region, the reaction rate increases with temperature linearly.

\section{Conclusion}

The airship fabric bag emissions of dilute hydrogen can be used for fuels in the stratosphere. The $\mathrm{Pd} / \gamma-\mathrm{Al}_{2} \mathrm{O}_{3}$ catalyst was prepared by impregnation method. The reaction kinetics of $\mathrm{H}_{2}$ in atmospheric pressure and low pressure (of $5.5 \mathrm{kPa}$ ) were investigated. The parameter of pressure has a little positive effect on $\mathrm{H}_{2}$ conversion performance with the pressure varying from $3.6 \mathrm{kPa}$ to $101.3 \mathrm{kPa}$. The increase of temperature leads to the

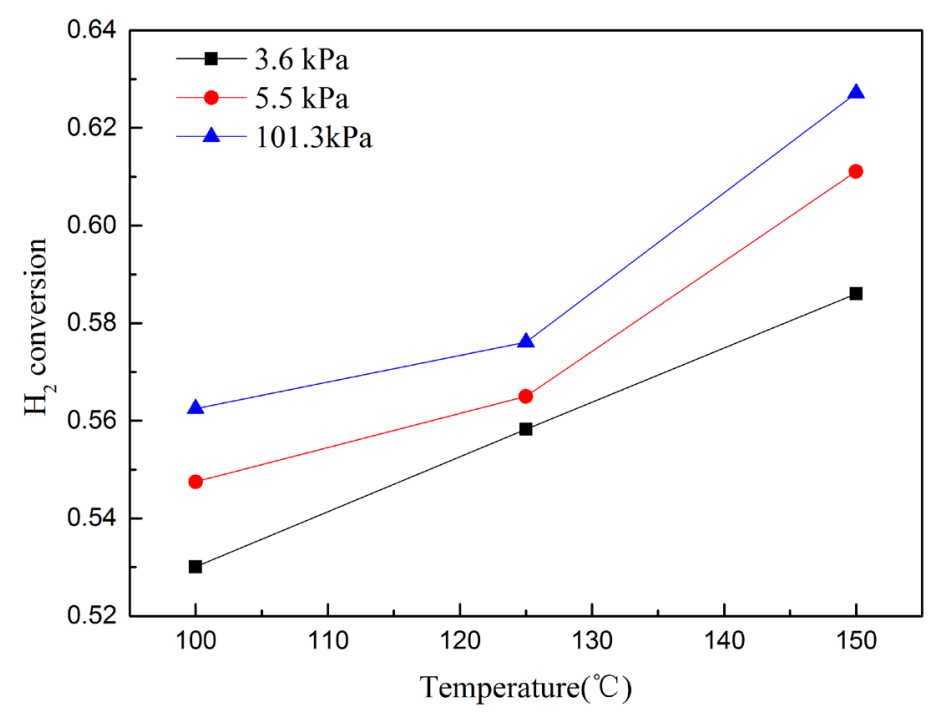

Figure 5. Hydrogen conversion of different temperatures at equivalence ratio of 0.3 . 

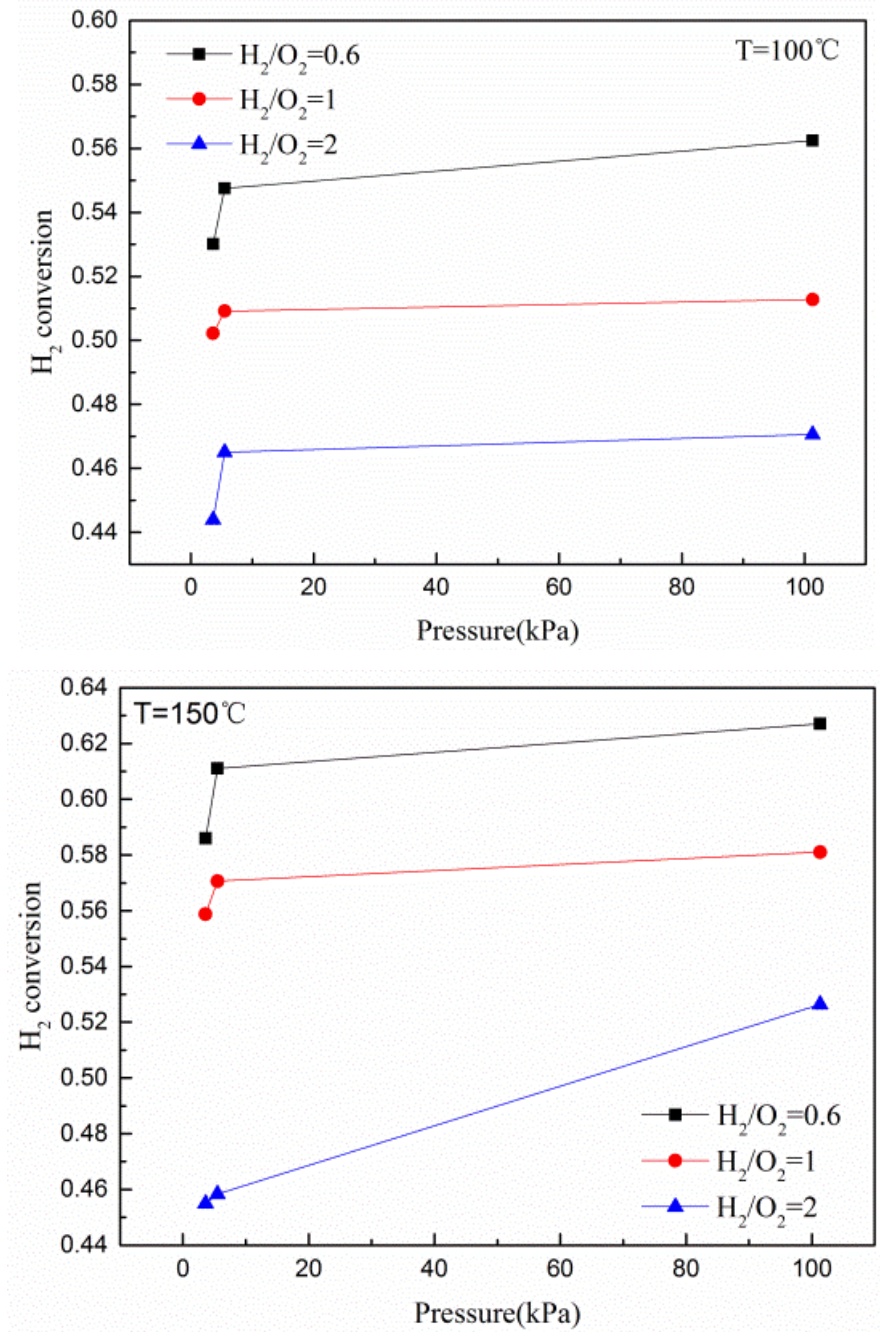

Figure 6. Hydrogen conversion of different $\mathrm{H}_{2}$ to $\mathrm{O}_{2}$ ratios at $100^{\circ} \mathrm{C}$ and $150^{\circ} \mathrm{C}$.

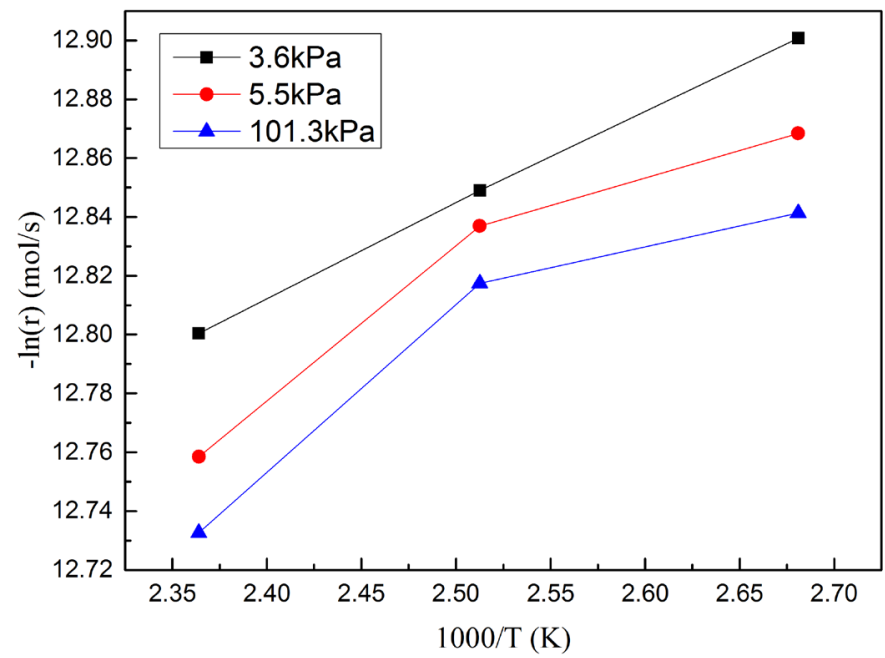

Figure 7. Reaction rates of $\mathrm{H}_{2}$ between $100^{\circ} \mathrm{C}$ and $150^{\circ} \mathrm{C}$ at different pressures. 
Table 3. Reaction rates of $\mathrm{H}_{2}$ in different pressures.

\begin{tabular}{|c|c|}
\hline p (kPa) & $r(\mathrm{~mol} / \mathrm{s})$ \\
\hline 3.6 & $r=\exp \left(-\frac{316.4}{T}-12.053\right)$ \\
\hline 5.5 & $r=\exp \left(-\frac{343.2}{T}-11.957\right)$ \\
\hline 101.3 & $r=\exp \left(-\frac{338.8}{T}-11.944\right)$ \\
\hline
\end{tabular}

increase of $\mathrm{H}_{2}$ conversion. And low concentration of $\mathrm{H}_{2}$ is beneficial for $\mathrm{H}_{2}$ conversion performance due to the inhibited surface diffusion processes. The reaction rates of $\mathrm{H}_{2}$ on the dependence of temperature at three pressures are given. Results suggest that the effect of temperature becomes more sensitive at high pressure. The reaction rate of $\mathrm{H}_{2}$ is also higher in high pressure conditions.

\section{Acknowledgements}

This work is supported by China Academy of the Space Technology (The Fifth Research Institute) and Tsinghua University.

\section{References}

[1] Pfefferle, L.D. and Pfefferle, W.C. (1987) Catalysis in Combustion. Catalysis Reviews: Science and Engineering, 29, 219-267. http://dx.doi.org/10.1080/01614948708078071

[2] Hardiyanto, W., Koshi, S., Koichi, E. and Hiromichi, A. (1999) Oxidation of Methane over Pd/Mixed Oxides for Catalytic Combustion. Catalysis Today, 47, 95-101. http://dx.doi.org/10.1016/S0920-5861(98)00286-7

[3] Kikuchi, R., Maeda, S., Sasaki, K., et al. (2003) Catalytic Activity of Oxide-Supported Pd Catalysts on a Honeycombfor Low-Temperature Methane Oxidation. Applied Catalysis A, 239, 169-179. http://dx.doi.org/10.1016/S0926-860X(02)00387-3

[4] Soraia, T.B., Emerson, A.S., Luca, L., et al. (2006) Methane Combustion over PdO-Alumina Catalysts: The Effect of Palladium Precursors. Applied Catalysis B, 63, 9-14. http://dx.doi.org/10.1016/j.apcatb.2005.08.009

[5] Deutschmann, O., Behrendt, F. and Wamatz, J. (1994) Modelling and Simulation of Heterogeneous Oxidation of Methane on a Platinum Foil. Catalysis Today, 21, 461-470. http://dx.doi.org/10.1016/0920-5861(94)80168-1

[6] Marco, S. and John, M. (2013) Hetero-/Homogeneous Combustion of Hydrogen/Air Mixtures over Platinum: Fuel-Lean versus Fuel-Rich Combustion Modes. International Journal of Hydrogen Energy, 38, 10654-10670. http://dx.doi.org/10.1016/j.ijhydene.2013.06.069

[7] Thevenin, P. (2002) Catalytic Combustion of Methane. Ph.D. Thesis, KTH-Kungliga Tekniska Högskolan.

[8] Kramer, J.F., Reihani, S.-A.S. and Jackson, G.S. (2002) Low-Temperature Combustion of Hydrogen on Supported Pd Catalysts. Proceedings of the Combustion Institute, 29, 989-996. http://dx.doi.org/10.1016/S1540-7489(02)80125-0

[9] Jin, L.Y., He, M., Lu, J.Q., et al. (2008) Palladium Catalysts Supported on Novel $\mathrm{Ce}_{\mathrm{x}} \mathrm{Y}_{1-\mathrm{x}} \mathrm{O}$ Washcoats for Toluene Catalytic Combustion. Journal of Rare Earths, 26, 614-618. http://dx.doi.org/10.1016/S1002-0721(08)60148-9

[10] Kikuchi, R., Maeda, S., Sasaki, K., Wennerström, S., Ozawa, Y. and Eguchi, K. (2003) Catalytic Activity of OxideSupported Pd Catalysts on a Honeycomb for Low-Temperature Methane Oxidation. Applied Catalysis A: General, 239, 169-179. http://dx.doi.org/10.1016/S0926-860X(02)00387-3

[11] Zhang, J.M. and Lu, Y.P. (2007) Research on Equilibrium Point Estimation of Stratospheric Balloon Trajectory Control System. Aerospace Control, 25, 4-9.

[12] Reinke, M., Mantzaras, J., Schaeren, R., et al. (2004) High Pressure Catalytic Combustion of Methane over Platinum: In Situ Experiments and Detailed Numerical Predictions. Combustion and Flame, 136, 217-240. http://dx.doi.org/10.1016/j.combustflame.2003.10.003 